BRAVZULIAN JOURNAL

OF MEDICAL AND BIOLOGICAL RESFARCH

www.bjournal.com.br
ISSN 0100-879X

Volume 44 (6) 497-605 June 2011

BIOMEDICAL SCIENCES

AND

CLINICAL INVESTIGATION

Braz J Med Biol Res, June 2011, Volume 44(6) 573-582

doi: 10.1590/S0100-879X2011007500049

Cardiac and renal effects induced by different exercise workloads in renovascular hypertensive rats

E.R. Soares, W.G. Lima, R.P. Machado, C.M. Carneiro, M.E. Silva, M.C. Rodrigues, U.G. De Castro, R.A.S. Santos, M.J. Campagnole-Santos and A.C. Alzamora

The Brazilian Journal of Medical and Biological Research is partially financed by

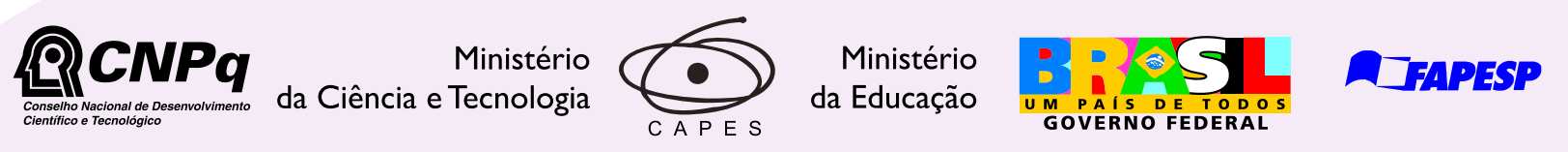

Institutional Sponsors
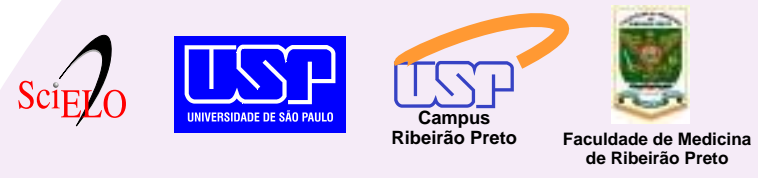
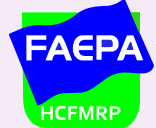

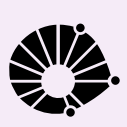

$\oplus$ SHIMADZU

GE Healthcare
Hotsite of proteomics metabolomics developped by:

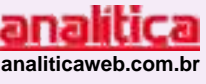

Thermo SCIENTIFIC 


\title{
Cardiac and renal effects induced by different exercise workloads in renovascular hypertensive rats
}

\author{
E.R. Soares 2,4 , W.G. Lima1,2,4 , R.P. Machado ${ }^{1,2,4}$, C.M. Carneiro2, \\ M.E. Silva2,4, M.C. Rodrigues ${ }^{2}$, U.G. De Castro ${ }^{2,4}$, R.A.S. Santos 3,4 , \\ M.J. Campagnole-Santos ${ }^{3,4}$ and A.C. Alzamora ${ }^{1,2,4}$ \\ ${ }^{1}$ Departamento de Ciências Biológicas, Instituto de Ciências Exatas e Biológicas, \\ 2Núcleo de Pesquisa em Ciências Biológicas, Universidade Federal de Ouro Preto, Ouro Preto, MG, Brasil \\ ${ }^{3}$ Departamento de Fisiologia e Biofísica, Instituto de Ciências Biológicas, \\ Universidade Federal de Minas Gerais, Belo Horizonte, MG, Brasil \\ ${ }^{4}$ Instituto Nacional de Ciência e Tecnologia em Inovação Nano-Biofarmacêutica, Belo Horizonte, MG, Brasil
}

\begin{abstract}
We examined the effect of exercise training (Ex) without (Ex 0\%) or with a 3\% workload (Ex $3 \%)$ on different cardiac and renal parameters in renovascular hypertensive (2K1C) male Fisher rats weighing 150-200 g. Ex was performed for 5 weeks, $1 \mathrm{~h} /$ day, 5 days/week. Ex $0 \%$ or Ex $3 \%$ induced similar attenuation of baseline mean arterial pressure (MAP, $119 \pm 5 \mathrm{mmHg}$ in $2 \mathrm{~K} 1 \mathrm{C}$ Ex $0 \%, \mathrm{~N}=6$, and $118 \pm 5 \mathrm{mmHg}$ in $2 \mathrm{~K} 1 \mathrm{C}$ Ex $3 \%, \mathrm{~N}=11$, vs $99 \pm 4 \mathrm{mmHg}$ in sham sedentary (Sham Sed) controls, $\mathrm{N}=10$ ) and heart rate $(\mathrm{HR}, \mathrm{bpm})(383 \pm 13$ in $2 \mathrm{~K} 1 \mathrm{C}$ Ex $0 \%, \mathrm{~N}=6$, and $390 \pm 14$ in $2 \mathrm{~K} 1 \mathrm{C}$ Ex $3 \%, \mathrm{~N}=11$ vs $371 \pm 11$ in Sham Sed, $\mathrm{N}=10)$. Ex $0 \%$, but not Ex $3 \%$, improved baroreflex bradycardia $(0.26 \pm 0.06 \mathrm{~ms} / \mathrm{mmHg}, \mathrm{N}=6, v s 0.09 \pm 0.03 \mathrm{~ms} / \mathrm{mmHg}$ in $2 \mathrm{~K} 1 \mathrm{C}$ Sed, $\mathrm{N}=11$ ). Morphometric evaluation suggested concentric left ventricle hypertrophy in sedentary $2 \mathrm{~K} 1 \mathrm{C}$ rats. Ex $0 \%$ prevented concentric cardiac hypertrophy, increased cardiomyocyte diameter and decreased cardiac vasculature thickness in $2 \mathrm{~K} 1 \mathrm{C}$ rats. In contrast, in $2 \mathrm{~K} 1 \mathrm{C}$, Ex $3 \%$ reduced the concentric remodeling and prevented the increase in cardiac vasculature wall thickness, decreased the cardiomyocyte diameter and increased collagen deposition. Renal morphometric analysis showed that Ex $3 \%$ induced an increase in vasculature wall thickness and collagen deposition in the left kidney of 2K1C rats. These data suggest that Ex $0 \%$ has more beneficial effects than Ex $3 \%$ in renovascular hypertensive rats.
\end{abstract}

Key words: Cardiac and renal remodeling; Baroreflex bradycardia; Different exercise workload; Renovascular hypertension

\section{Introduction}

Accumulating evidence shows that overactivity of the sympathetic nervous system and renin-angiotensin system (RAS) plays a crucial role in the development and maintenance of hypertension (1). The main cardiovascular feature of hypertension is high blood pressure (BP) and impaired baroreflex function. Cardiac hypertrophy is an important process of adaptation to an increased workload in response to a physiological (exercise training) or pathological (hypertension) stimulus.

The compensatory hemodynamic overload response results in increased cardiac mass, presenting as ventricular hypertrophy. The parallel addition of sarcomeres causes an increase in myocyte width, which in turn increases the thickness of the wall. This remodeling results in concentric hypertrophy, which occurs in hypertensive states and in exercise training that requires isometric skeletal muscle contraction $(2,3)$. Isotonic exercise engenders myocyte lengthening through replication of sarcomeres in series, and an increase in ventricular volume, resulting in eccentric hypertrophy $(3,4)$.

It is now well accepted that exercise training produces beneficial effects on the cardiovascular system in hypertensive conditions through central and peripheral neurohumoral modulations. The cardiovascular adjustments in response to exercise training occur in order to maintain proper BP and to efficiently adjust the blood supply to different vascular beds

Correspondence: A.C. Alzamora, Departamento de Ciências Biológicas, Universidade Federal de Ouro Preto, Morro do Cruzeiro, 35400-000 Ouro Preto, MG, Brasil. Fax: +55-31-3559-1633. E-mail: andreiaalzamora@iceb.ufop.br

Received October 7, 2010. Accepted April 6, 2011. Available online April 25, 2011. Published June 13, 2011. 
according to regional metabolic demands. The effects of exercise training include reductions in sympathetic outflow, vascular resistance, and plasma angiotensin (Ang) II levels; an improvement in the sensitivity of the baroreflex control of the heart rate (HR), and cardiac remodeling. These effects occur with a simultaneous increase in stroke volume and decreases in HR and BP in chronic heart failure (CHF) (5) in spontaneously hypertensive rats (SHR) (6-8) and in renovascular hypertension two-kidney one-clip (2K1C) rats $(9,10)$.

In spite of the consistent findings regarding the beneficial cardiovascular effects induced by exercise training, adaptations to exercise depend on factors such as training load, duration, and frequency of exercise training $(6,11,12)$. Moderately intensive exercise training is recognized as having more beneficial effects on the cardiovascular system than higher-intensity exercise training in animals and humans with hypertension $(6,13-15)$.

In a previous study (10), we showed that low-intensity exercise training is effective in lowering BP and restoring the sensitivity of the baroreflex bradycardia in $2 \mathrm{~K} 1 \mathrm{C}$ hypertensive rats. The renovascular hypertensive $2 \mathrm{~K} 1 \mathrm{C}$ rat is characterized by high levels of tissue and circulating RAS components, and by a high level of sympathetic nerve discharge $(16,17)$. The present study compared the effect induced by exercise training (Ex) on renovascular hypertensive rats, either without (Ex $0 \%$ ) or with a workload corresponding to $3 \%$ of the animal's body weight (Ex $3 \%$ ), on $\mathrm{BP}, \mathrm{HR}$, sensitivity of the baroreflex bradycardia, renal morphometric structures, and cardiac remodeling.

\section{Material and Methods}

\section{Animals}

The experiments were performed on male Fisher rats ( $N=85$; Escola de Nutrição, Universidade Federal de Ouro Preto, Brazil). All animal procedures were carried out according to the Guidelines for Ethical Care of Experimental Animals, and were approved by the Institutional Ethics Committee of Universidade Federal de Ouro Preto, Ouro Preto, MG, Brazil.

\section{Production of renovascular hypertension}

Renovascular hypertension was induced as described previously (10). Rats (150-200 g) were anesthetized with a mixture of ketamine and xylazine $(50$ and $10 \mathrm{mg} / \mathrm{kg}$, ip, respectively) (Syntec, Brazil) and a silver clip (0.20 mm ID) was placed around the left renal artery through a midline incision (Goldblatt renovascular hypertension, 2K1C). Other rats were subjected to similar procedures but without placement of the renal artery clip (Sham group or normotensive rats). The $2 \mathrm{~K} 1 \mathrm{C}$ and Sham rats were divided into three experimental groups: sedentary (Sed), exercise training without (Ex 0\%) or with a workload (Ex 3\%). The training protocol was started 4 days after surgery.

\section{Exercise training protocol}

The rats were subjected to swimming Ex $0 \%$ or Ex $3 \%$ for 5 weeks, 1 h/day, 5 days/week. The Ex $0 \%$ protocol was performed according to a previously described method $(10,18)$. The Ex $3 \%$ protocol was adapted from Galdino and Mello (19). The load was obtained by a screw-nut or washer fixed on the tail of each animal, from the 6th session of exercises on. For adaptive purposes, from the 6th to the 8th session of swimming, the load used was $2 \%$ of body weight. From the 9th session on, the load used was $3 \%$ of the animal's body weight. The exercise was performed by groups of 4 rats in a $38 \times 60 \times 50-\mathrm{cm}$ tank. Water temperature was maintained at approximately $30^{\circ} \mathrm{C}$, controlled by a thermostat. Sedentary rats were placed in the swimming apparatus with shallow water for $40 \mathrm{~min}, 5$ days/week to mimic the water stress associated with the experimental protocol.

\section{Arterial pressure measurements}

Mean arterial pressure (MAP) was determined in conscious rats, 1 day a week for five weeks, by the tail-cuff method in order to monitor the development of renovascular hypertension and the effect of exercise training on BP. At the end of the 5th week, $48 \mathrm{~h}$ after the end of the Ex and Sed protocols, the rats were anesthetized with urethane, $1.2 \mathrm{~g} / \mathrm{kg}$ body weight (Sigma, USA), for direct cardiovascular evaluation $(10,20)$. Pulsatile arterial pressure was monitored with a Gould pressure transducer (PM-1000, CWE, USA) coupled to a BP signal amplifier (UIM100A, Powerlab System, AD Instruments, USA). MAP and $H R$ were determined by the arterial pressure waves. All variables were recorded and saved in a PowerLab digital acquisition system (Powerlab 4/20, AD Instruments) with an $800-\mathrm{Hz}$ sampling rate.

\section{Evaluation of baroreflex sensitivity}

Baroreflex control of HR was determined by recording reflex $H R$ changes in response to transient increases in MAP produced by repeated bolus injections of graded doses of phenylephrine ( 0.25 to $5 \mu \mathrm{g}$, iv; Sigma) in urethane-anesthetized rats $(1.2 \mathrm{~g} / \mathrm{kg}$ body weight) as previously described by Alzamora et al. (20) and Rodrigues et al. (10).

\section{Analysis of cardiac and renal structures}

For the morphometric analyses, hearts and kidneys were collected and fixed in $10 \%$ neutral-buffered formalin solution. Next, the hearts and kidneys were dehydrated, cleared, and embedded in paraffin. The paraffin block was cut into 4-5- $\mu \mathrm{m}$ thick sections, and adjacent sections were stained with hematoxylin/eosin for evaluation of general myocardial and renal damage, or by Masson's trichrome for quantification of collagen tissue deposition. All morphometric measurements were made in tissue sections under a light microscope (Leica DM5000) and analyzed with the Leica 
Qwin Image Processing and Analysis Software (Germany). Cardiomyocyte diameter was measured by the method described by Loud et al. (21) in light microscope images at 40X magnification. The left ventricle wall thickness $(\mathrm{Wt})$ and ventricle lumen $(L)$ were determined on sections at $5 X$ magnification (adapted from Ref. 22), and the degree of cardiac hypertrophy was calculated as the ratio between the left ventricle wall thickness and the left ventricle lumen (Wt/L). A similar morphometric method was used to obtain the thicknesses of the wall and lumen of the cardiac and renal arteries. Higher values of the $\mathrm{Wt} / \mathrm{L}$ ratio indicated concentric hypertrophy, and lower values of the $\mathrm{Wt} / \mathrm{L}$ ratio characterized an eccentric hypertrophy. Since Sham Sed rats did not present changes in these ratios, the $\mathrm{Wt} / \mathrm{L}$ ratio of these animals was used as control. Morphometric analysis was also used to quantify the cardiac and renal inflammatory process and tissue collagen deposition as described by Caliari et al. (23) and de Paula Costa et al. (24). Two groups of rats were used: one group $(\mathrm{N}=4-8)$ was used to evaluate the dry weight of kidneys and heart, and the other $(\mathrm{N}=4)$ for the morphometric analyses.

\section{Lactate measurement}

Lactate production. In order to evaluate the effect of exercise training on blood lactate production in $2 \mathrm{~K} 1 \mathrm{C}(\mathrm{N}=$ 4) or Sham $(\mathrm{N}=4)$ Sed, Ex $0 \%$, and Ex 3\% rats, a single swimming session with a load of $3 \%$ of body weight was performed for $30 \mathrm{~min}, 48 \mathrm{~h}$ after the last session of the exercise program. Immediately after this swimming session, a blood sample $(25 \mu \mathrm{L})$ was collected by cutting the tip of the tail for lactate determination. The lactate concentrations were determined with a lactate analyzer (Accutrend ${ }^{\circledR}$ Lactate, Roche, Germany) according to manufacturer instructions.

\section{Statistical analysis}

Data are reported as means \pm SEM. Comparisons among different groups were performed by one-way ANOVA followed by the Newman-Keuls test, using the Graphpad Prism software (version 4.00). The criterion for statistical significance was set at $\mathrm{P}<0.05$.

\section{Results}

\section{MAP and HR measurements}

Figure 1 shows the MAP levels of Sham and 2K1C Sed rats and rats subjected to Ex during the 5 weeks after surgery. The 2K1C (Sed, Ex 0\% and Ex 3\%) animals showed higher levels of tail MAP compared to the Sham Sed group, from the second experimental week (2-5 weeks) after surgery. However, Ex $0 \%$ and Ex $3 \%$ attenuated the increase in MAP in $2 \mathrm{~K} 1 \mathrm{C}$ rats, beginning at the fourth week. MAP did not differ significantly between the Sham Ex groups ( 0 and $3 \%$ ) and Sham Sed rats (data not shown).

After 5 weeks, the rats were anesthetized for evaluation of the cardiovascular parameters. The baseline MAP of $2 \mathrm{~K} 1 \mathrm{C}$ Sed rats $(130 \pm 5 \mathrm{mmHg}, \mathrm{N}=11)$ was significantly higher than the baseline MAP of Sham Sed rats $(99 \pm 4$ $\mathrm{mmHg}, \mathrm{N}=10)$. The MAPs of $2 \mathrm{~K} 1 \mathrm{C}$ Ex $0 \%$ rats $(119 \pm 5$ $\mathrm{mmHg}, \mathrm{N}=6)$ or $2 \mathrm{~K} 1 \mathrm{C}$ Ex $3 \%$ rats $(118 \pm 5 \mathrm{mmHg}, \mathrm{N}=$ 11) did not differ from the MAP of Sham Sed rats (Figure 2A). Baseline MAP did not differ significantly between the Sham trained group $(98 \pm 2 \mathrm{mmHg}, \mathrm{N}=6$, Ex $0 \%$ and $99 \pm$ $4 \mathrm{mmHg}, \mathrm{N}=9$, Ex 3\%) and Sham Sed rats (Figure 2A).

The baseline values of HR were significantly higher in the $2 \mathrm{~K} 1 \mathrm{C}$ Sed group ( $439 \pm 9 \mathrm{bpm}, \mathrm{N}=11$ ) than in Sham Sed rats $(371 \pm 11 \mathrm{bpm}, \mathrm{N}=10)$. However, the baseline values of $\mathrm{HR}$ in $2 \mathrm{~K} 1 \mathrm{C}$ Ex $0 \%$ rats $(383 \pm 13 \mathrm{bpm}, \mathrm{N}=6)$ and in the $2 \mathrm{~K} 1 \mathrm{C}$ Ex $3 \%$ rats (390 $\pm 14 \mathrm{bpm}, \mathrm{N}=11$ ) were significantly lower than in $2 \mathrm{~K} 1 \mathrm{C}$ Sed rats, and were similar to that of Sham Sed rats (Figure 2B). The baseline values of HR of the Sham Ex $0 \%$ rats $(363 \pm 13 \mathrm{bpm}, \mathrm{N}=6)$ and Sham Ex $3 \%$ rats $(369 \pm 13 \mathrm{bpm}, \mathrm{N}=9)$ were similar to that of the Sham Sed rats (Figure $2 \mathrm{~B}$ ).

\section{Evaluation of the sensitivity of baroreflex bradycardia}

As expected, the reflex bradycardia of $2 \mathrm{~K} 1 \mathrm{C}$ Sed rats $(0.09 \pm 0.03 \mathrm{~ms} / \mathrm{mmHg}, \mathrm{N}=11$, Figure $2 \mathrm{C})$ was significantly lower than that of Sham Sed rats $(0.37 \pm 0.05 \mathrm{~ms} / \mathrm{mmHg}$, $\mathrm{N}=10$ ). There was no significant difference in baroreflex bradycardia between the sedentary and trained Sham groups $(0.30 \pm 0.03 \mathrm{~ms} / \mathrm{mmHg}, \mathrm{N}=6$, in Sham Ex $0 \%$ group and $0.31 \pm 0.03 \mathrm{~ms} / \mathrm{mmHg}, \mathrm{N}=9$, in Sham Ex $3 \%$ group; Figure 2C). Conversely, 2K1C rats subjected to Ex $0 \%$ showed a significant increase in baroreflex bradycardia $(0.26 \pm 0.06 \mathrm{~ms} / \mathrm{mmHg}, \mathrm{N}=6)$ compared to $2 \mathrm{~K} 1 \mathrm{C}$ Sed, which was similar to the value of Sham Sed rats (Figure 2C). However, in $2 \mathrm{~K} 1 \mathrm{C}$ animals subjected to Ex $3 \%$, there was no change in attenuated baroreflex bradycardia $(0.08$ $\pm 0.02 \mathrm{~ms} / \mathrm{mmHg}, \mathrm{N}=11$; Figure $2 \mathrm{C}$ ).

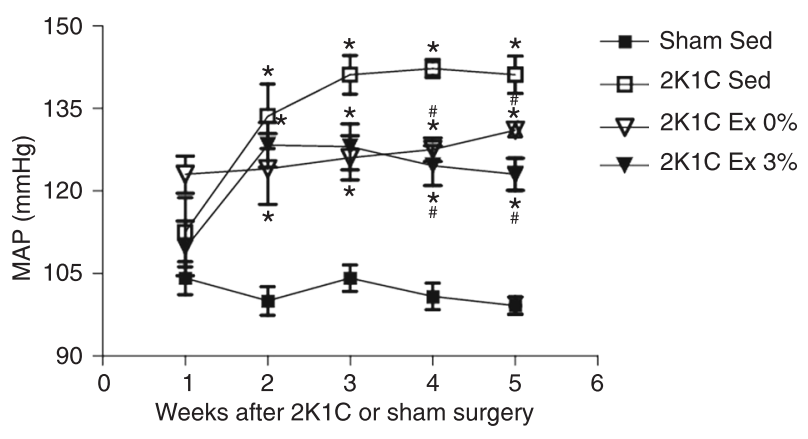

Figure 1. Tail-cuff mean arterial pressure (MAP, $\mathrm{mmHg}$ ) of Sham $(\mathrm{N}=6)$ and $2 \mathrm{~K} 1 \mathrm{C}(\mathrm{N}=6-12)$ sedentary (Sed) rats, and rats subjected to exercise training (Ex) without (Ex $0 \%$ ) or with a workload corresponding to $3 \%$ of the animal's body weight (Ex $3 \%$ ). ${ }^{*} \mathrm{P}<$ 0.05 compared to Sham Sed and ${ }^{\#} P<0.05$ compared to $2 \mathrm{~K} 1 \mathrm{C}$ Sed (ANOVA followed by the Newman-Keuls test). 


\section{Analysis of cardiac structure}

As shown in Table 1, the heart weight and left ventricle weight were higher in $2 \mathrm{~K} 1 \mathrm{C}$ Sed than in Sham Sed animals. Accordingly, the cardiomyocyte diameters of $2 \mathrm{~K} 1 \mathrm{C}$ Sed rats were significantly increased compared to those of Sham Sed
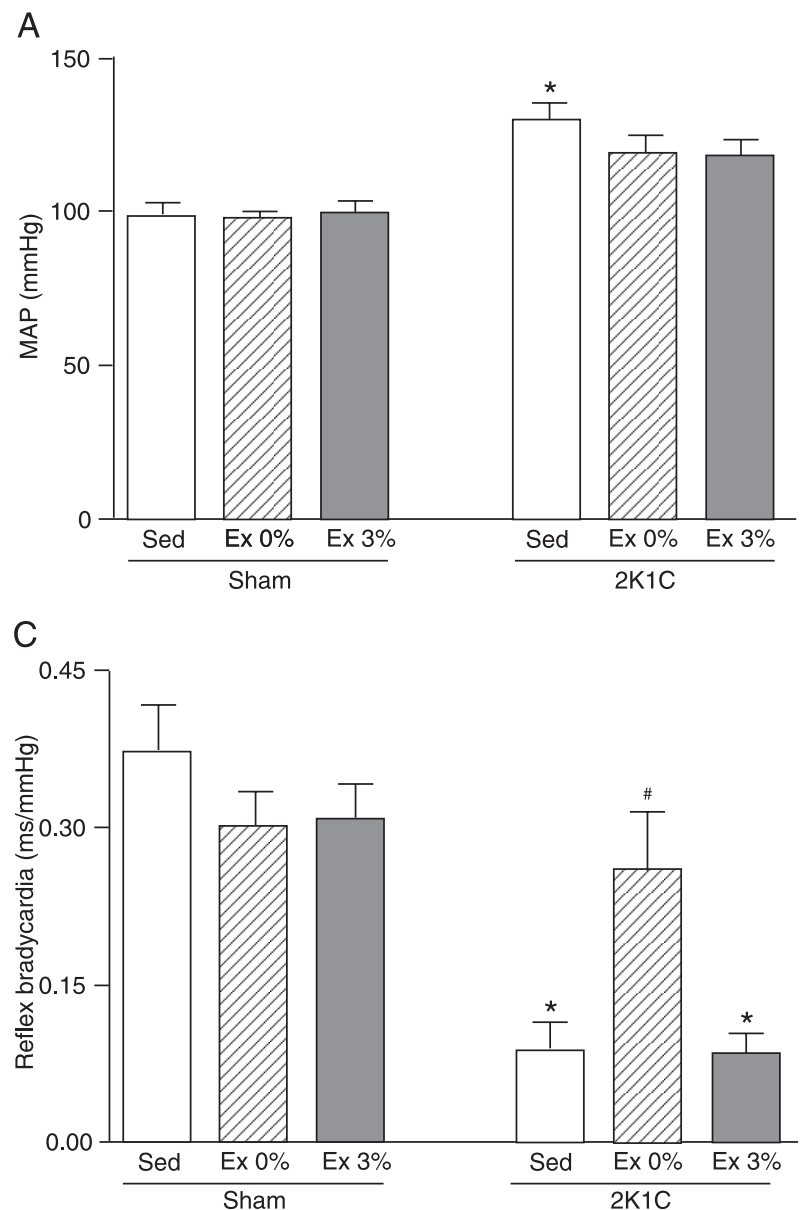

rats. However, no changes were observed in the number of myocardial cells (tissue inflammatory process) or tissue collagen deposition (Table 1 and Figure 3 ) between $2 \mathrm{~K} 1 \mathrm{C}$ Sed and Sham Sed rats. Ex $0 \%$ induced an increase in cardiomyocyte diameter in Sham and $2 \mathrm{~K} 1 \mathrm{C}$ rats compared

B

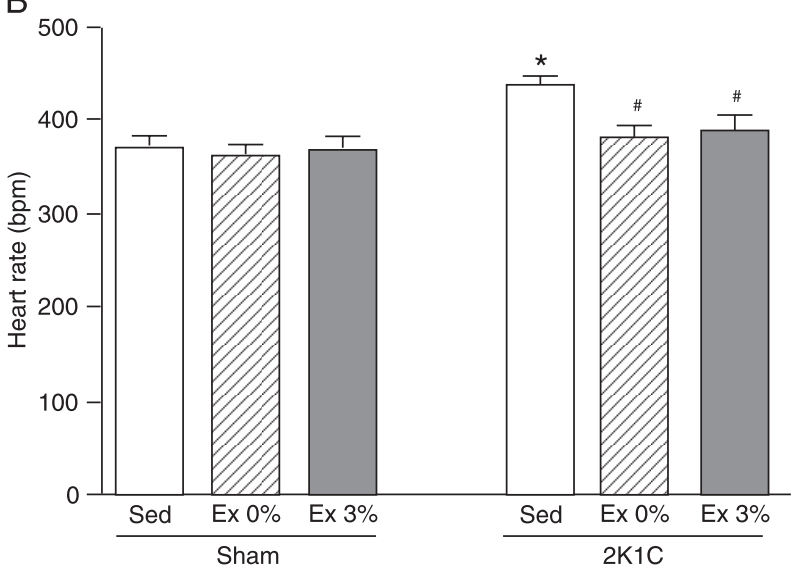

Figure 2. Baseline values of mean arterial pressure (MAP; panel $A$ ), heart rate (panel $B$ ) and reflex bradycardia (panel C) of Sham $(\mathrm{N}=6-10)$ and $2 \mathrm{~K} 1 \mathrm{C}(\mathrm{N}=6-11)$ sedentary (Sed) rats, and rats subjected to exercise training (Ex) without (Ex $0 \%$ ) or with a workload corresponding to $3 \%$ of the animal's body weight (Ex $3 \%)$. ${ }^{*} P<0.05$ compared to Sham Sed and \#P $<0.05$ compared to $2 \mathrm{~K} 1 \mathrm{C}$ Sed (ANOVA followed by the Newman-Keuls test).

Table 1. Morphometric analysis of cardiac changes in sedentary rats (Sed) and rats subjected to exercise training (Ex) without a load (Ex $0 \%)$ or with a load corresponding to $3 \%$ of the animal's body weight (Ex $3 \%)$.

\begin{tabular}{|c|c|c|c|c|c|c|}
\hline & \multicolumn{3}{|c|}{ Sham } & \multicolumn{3}{|c|}{$2 \mathrm{~K} 1 \mathrm{C}$} \\
\hline & $\begin{array}{c}\text { Sed } \\
(N=4-7)\end{array}$ & $\begin{array}{c}\text { Ex 0\% } \\
(\mathrm{N}=4-6)\end{array}$ & $\begin{array}{c}\text { Ex } 3 \% \\
(\mathrm{~N}=4-7)\end{array}$ & $\begin{array}{l}\text { Sed } \\
(N=4)\end{array}$ & $\begin{array}{l}\text { Ex } 0 \% \\
(N=4)\end{array}$ & $\begin{array}{c}\text { Ex } 3 \% \\
(\mathrm{~N}=4-7)\end{array}$ \\
\hline Heart dry weight/tibia length (mg/mm) & $5.1 \pm 0.2$ & $4.6 \pm 0.1$ & $4.7 \pm 0.1$ & $6.1 \pm 0.2^{*}$ & $4.9 \pm 0.3^{\#}$ & $5.8 \pm 0.3^{*}$ \\
\hline Left ventricle dry weight/tibia length (mg/mm) & $2.7 \pm 0.1$ & $2.6 \pm 0.1$ & $2.6 \pm 0.1$ & $3.4 \pm 0.2^{*}$ & $2.8 \pm 0.2^{\#}$ & $3.3 \pm 0.2^{*}$ \\
\hline Cardiomyocyte diameter $(\mu \mathrm{m})$ & $12.7 \pm 0.2$ & $16.3 \pm 0.3^{*}$ & $10.7 \pm 0.1^{*}$ & $13.8 \pm 0.2^{*}$ & $16.1 \pm 0.2^{* \#}$ & $11.9 \pm 0.2^{* \#}$ \\
\hline Left ventricle wall thickness/lumen ratio (Wt/L) & $0.5 \pm 0.05$ & $0.6 \pm 0.02$ & $0.4 \pm 0.02$ & $0.9 \pm 0.04^{*}$ & $0.6 \pm 0.06^{\#}$ & $0.7 \pm 0.04^{\star \#}$ \\
\hline Cardiac vasculature wall thickness/lumen ratio (Wt/L) & $0.23 \pm 0.02$ & $0.21 \pm 0.02$ & $0.23 \pm 0.01$ & $0.31 \pm 0.02^{*}$ & $0.22 \pm 0.01^{\#}$ & $0.27 \pm 0.02$ \\
\hline Myocardial cell number (total area $1.5 \times 10^{7} \mu \mathrm{m}^{2}$ ) & $136 \pm 7$ & $103 \pm 8^{*}$ & $167 \pm 11^{*}$ & $121 \pm 4$ & $128 \pm 6$ & $152 \pm 5^{\#}$ \\
\hline Myocardial tissue collagen deposition $\left(\mu \mathrm{m}^{2}\right)$ & $92 \pm 13$ & $89 \pm 17$ & $153 \pm 24$ & $103 \pm 20$ & $157 \pm 30$ & $277 \pm 81^{* \#}$ \\
\hline
\end{tabular}

Data are reported as means \pm SEM. $2 \mathrm{~K} 1 \mathrm{C}=2$-kidney, 1-clip model. ${ }^{*} \mathrm{P}<0.05$ compared to Sham Sed; \# $<0.05$ compared to $2 \mathrm{~K} 1 \mathrm{C}$ Sed (ANOVA followed by the Newman-Keuls test). 
to Sham Sed rats. However, no change was observed in the heart weight or left ventricle weight or in the deposition of tissue collagen in either Ex $0 \%$ group (Sham and $2 \mathrm{~K} 1 \mathrm{C}$ ) compared to the Sham Sed group (Table 1). Nevertheless, Ex $3 \%$ induced an increase in heart weight or in left ventricle weight in $2 \mathrm{~K} 1 \mathrm{C}$ rats compared to Sham Sed rats (Table 1). Interestingly, a reduction in cardiomyocyte diameter was observed in $2 \mathrm{~K} 1 \mathrm{C}$ rats subjected to Ex $3 \%$. In addition, the number of myocardial cells (predominantly mononuclear cells), which was used as an index of the inflammatory process, was increased in $2 \mathrm{~K} 1 \mathrm{C}$ rats subjected to Ex $3 \%$ compared to $2 \mathrm{~K} 1 \mathrm{C}$ Sed rats (Table 1 and Figure 3), while tissue collagen deposition in $2 \mathrm{~K} 1 \mathrm{C}$ subjected to Ex $3 \%$ was larger compared to Sham or $2 \mathrm{~K} 1 \mathrm{C}$ Sed rats (Table 1 and Figure 3). Heart weight and left ventricle weight did not differ among Sham groups (Table 1). No differences in right ventricle weight were observed in any of the groups evaluated (Sham or 2K1C) (data not shown).

The $\mathrm{Wt} / \mathrm{L}$ ratio was higher in $2 \mathrm{~K} 1 \mathrm{C}$ Sed and $2 \mathrm{~K} 1 \mathrm{C}$ Ex $3 \%$ rats than in Sham Sed rats, suggesting concentric hypertrophy (Table 1). However, this ratio was lower in $2 \mathrm{~K} 1 \mathrm{C}$ Ex $3 \%$ rats than in $2 \mathrm{~K} 1 \mathrm{C}$ Sed rats. In addition, the left ventricle $\mathrm{Wt} / \mathrm{L}$ ratio of $2 \mathrm{~K} 1 \mathrm{C}$ Ex $0 \%$ rats was similar to that of Sham Sed rats. No difference was observed for the left ventricle $\mathrm{Wt} / \mathrm{L}$ ratio in Sham animals (Table 1 ). No differences in the right ventricle $\mathrm{Wt} / \mathrm{L}$ ratio were observed for any of the groups evaluated (data not shown).

The cardiac vasculature $\mathrm{Wt} / \mathrm{L}$ ratio was higher in $2 \mathrm{~K} 1 \mathrm{C}$ Sed rats than in Sham Sed rats (Table 1), and was lower in $2 \mathrm{~K} 1 \mathrm{C}$ Ex $0 \%$ rats than in $2 \mathrm{~K} 1 \mathrm{C}$ Sed rats (Table 1 ).

\section{Analysis of renal structure}

As shown in Table 2, the left (clipped) kidney of 2K1C Sed and $2 \mathrm{~K} 1 \mathrm{C}$ Ex $0 \%$ rats weighed less than the right (non-clipped) kidney in both groups. However, there was no significant compensatory increase in the non-clipped kidney weight in $2 \mathrm{~K} 1 \mathrm{C}$ Ex $3 \%$ rats compared to the weight of the contralateral left kidney (Table 2). Moreover, the non-clipped kidney weight of $2 \mathrm{~K} 1 \mathrm{C}$ Sed animals was higher than the right kidney weight of Sham Sed animals (Table 2). In contrast, the clipped kidney weight of $2 \mathrm{~K} 1 \mathrm{C}$ (Sed, Ex $0 \%$ or Ex $3 \%$ ) rats was lower than the left kidney weight of Sham Sed rats (Table 2). The left and right kidney weights did not differ among the Sham groups (Table 2).

As shown in Table 2, the left renal vascular $\mathrm{Wt} / \mathrm{L}$ ratio was higher only in $2 \mathrm{~K} 1 \mathrm{C}$ Ex $3 \%$ rats compared to the left

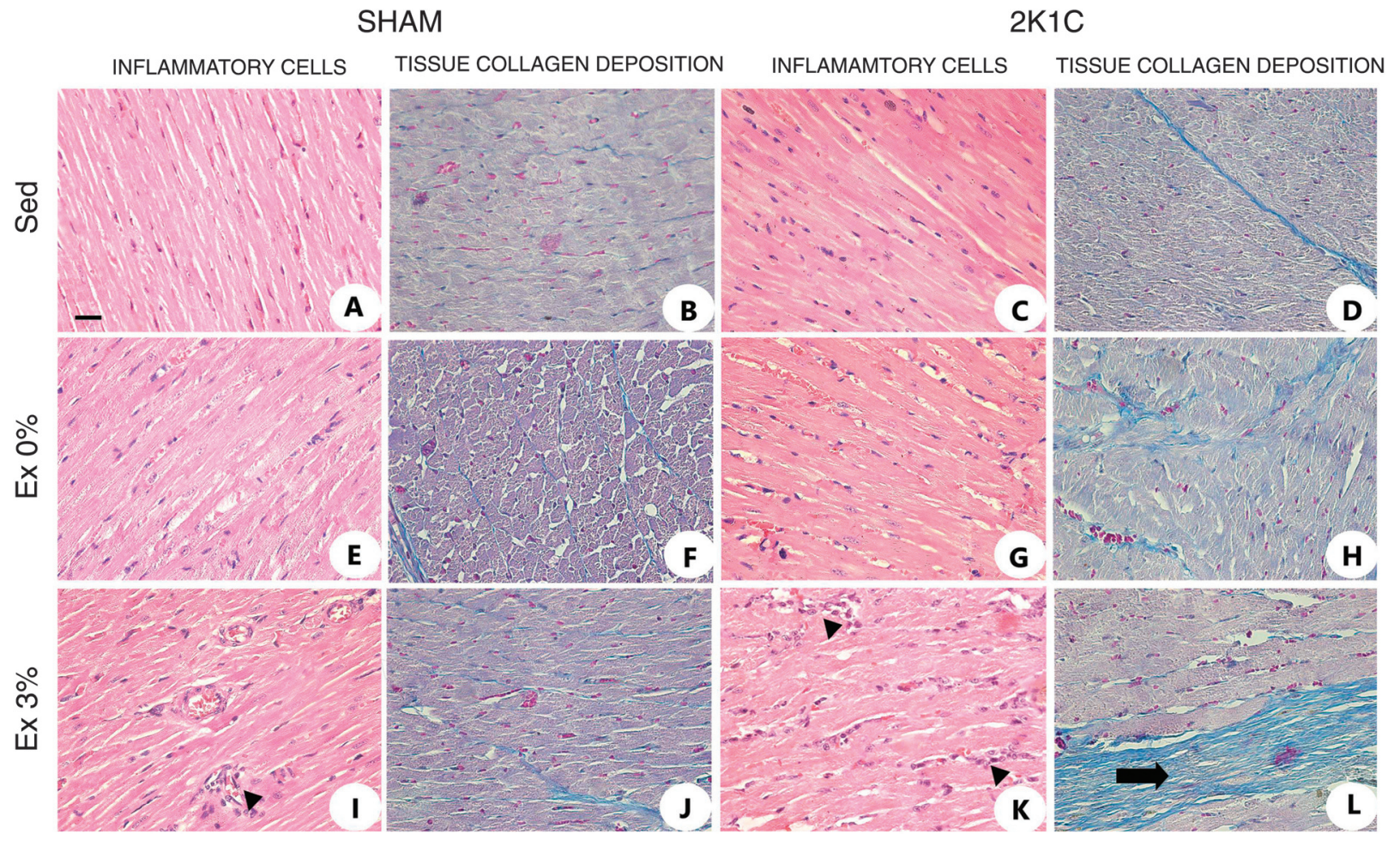

Figure 3. Photomicrographs of the heart ventricles of Sham and $2 \mathrm{~K} 1 \mathrm{C}$ sedentary (Sed) rats, and rats subjected to exercise training (Ex) without (Ex $0 \%)$ or with a load corresponding to $3 \%$ of the animal's body weight (Ex $3 \%)$. Normal histological inflammatory picture can be observed in Sed and Ex 0\% animals (A, C, E, and G). Observe the increase of inflammatory cells in Ex $3 \%$ rats (I and K, arrowheads). No pathological collagen tissue deposition was observed in animals Sed, Ex 0\% and Sham Ex 3\% (B, D, F, H, and J). Also observe the greater collagen deposition in 2K1C Ex 3\% rats (L, arrow). A, C, E, G, I, and K were stained with hematoxylin/eosin. B, D, $\mathrm{F}, \mathrm{H}, \mathrm{J}$, and L were stained with Masson's trichrome. All photomicrographs are enlarged 440 times (bar $=25 \mu \mathrm{m})$. 
kidney of Sham Sed rats, suggesting concentric hypertrophy in the left renal vasculature in this group. No differences were observed in the $\mathrm{Wt} / \mathrm{L}$ ratio of the right (non-clipped) kidney in any group (Sham or 2K1C; Table 2).

The number of left and right kidney cells in $2 \mathrm{~K} 1 \mathrm{C}$ Sed rats was higher than in the respective kidneys of Sham Sed rats (Table 2 and Figure 4). In addition, in 2K1C (Sed, Ex 0\%, and Ex $3 \%$ ) rats, only the clipped kidney, but not the non-clipped kidney, showed an increase in tissue collagen deposition compared to the left kidney of Sham Sed rats (Table 2 and

Table 2. Morphometric analysis of renal changes in sedentary rats (Sed) and rats submitted to exercise training (Ex) without a load (Ex $0 \%$ ) or with a load corresponding to $3 \%$ of the animal's body weight (Ex $3 \%$ ).

\begin{tabular}{|c|c|c|c|c|c|c|}
\hline & \multicolumn{3}{|c|}{ Sham } & \multicolumn{3}{|c|}{$2 \mathrm{~K} 1 \mathrm{C}$} \\
\hline & $\begin{array}{c}\text { Sed } \\
(N=4-8)\end{array}$ & $\begin{array}{c}\text { Ex } 0 \% \\
(N=4-6)\end{array}$ & $\begin{array}{c}\text { Ex } 3 \% \\
(N=4-7)\end{array}$ & $\begin{array}{c}\text { Sed } \\
(N=4-5)\end{array}$ & $\begin{array}{l}\text { Ex } 0 \% \\
(N=4)\end{array}$ & $\begin{array}{c}\text { Ex } 3 \% \\
(N=4-7)\end{array}$ \\
\hline Left kidney dry weight/tibia length (mg/mm) & $7.2 \pm 0.3$ & $5.7 \pm 0.1$ & $6.0 \pm 0.4$ & $5.6 \pm 0.6^{*+}$ & $3.9 \pm 0.7^{\star \#+}$ & $5.3 \pm 0.5^{*}$ \\
\hline Right kidney dry weight/tibia length (mg/mm) & $7.3 \pm 0.2$ & $5.7 \pm 0.2$ & $5.9 \pm 0.2$ & $9.5 \pm 0.5^{*}$ & $8.0 \pm 0.4^{\#}$ & $6.6 \pm 0.2^{\#}$ \\
\hline Left renal vasculature wall thickness/lumen ratio (Wt/L) & $0.46 \pm 0.03$ & $0.52 \pm 0.03$ & $0.50 \pm 0.03$ & $0.55 \pm 0.03$ & $0.48 \pm 0.03$ & $0.60 \pm 0.03^{*}$ \\
\hline Right renal vasculature wall thickness/lumen ratio (Wt/L) & $0.56 \pm 0.04$ & $0.43 \pm 0.02$ & $0.53 \pm 0.03$ & $0.55 \pm 0.04$ & $0.64 \pm 0.04$ & $0.51 \pm 0.03$ \\
\hline Left kidney cell number (total area $1.5 \times 10^{7} \mu \mathrm{m}^{2}$ ) & $347 \pm 8$ & $330 \pm 16$ & $315 \pm 13$ & $418 \pm 25^{\star}$ & $426 \pm 23^{*+}$ & $318 \pm 25^{\#}$ \\
\hline Right kidney cell number (total area $1.5 \times 10^{7} \mu \mathrm{m}^{2}$ ) & $310 \pm 22$ & $304 \pm 13$ & $280 \pm 16$ & $406 \pm 12^{*}$ & $287 \pm 12^{\#}$ & $303 \pm 22^{\#}$ \\
\hline Left kidney collagen deposition $\left(\mu \mathrm{m}^{2}\right)$ & $209 \pm 31$ & $144 \pm 15$ & $123 \pm 22$ & $638 \pm 118^{*}$ & $707 \pm 136^{*}$ & $988 \pm 140^{\star \#}$ \\
\hline Right kidney collagen deposition $\left(\mu \mathrm{m}^{2}\right)$ & $142 \pm 18$ & $153 \pm 36$ & $204 \pm 30$ & $136 \pm 21$ & $135 \pm 15$ & $110 \pm 9$ \\
\hline
\end{tabular}

Data are reported as means \pm SEM. $2 \mathrm{~K} 1 \mathrm{C}=2$-kidney, 1 -clip model. ${ }^{*} \mathrm{P}<0.05$ compared to Sham Sed. ${ }^{*} \mathrm{P}<0.05$ compared to $2 \mathrm{~K} 1 \mathrm{C}$ Sed; ${ }^{+} \mathrm{P}<0.05$ compared to right kidney (ANOVA followed by the Newman-Keuls test).

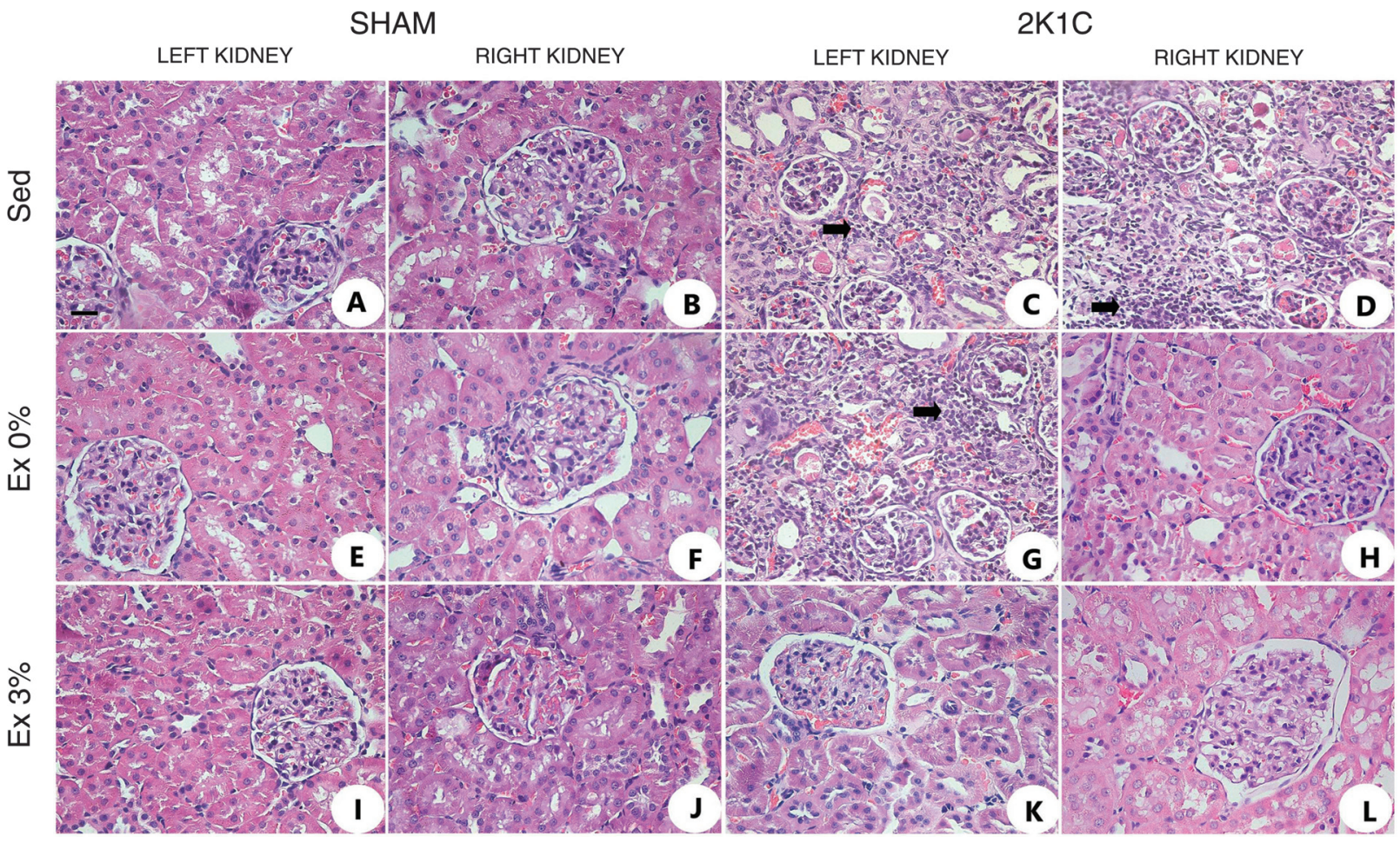

Figure 4. Photomicrographs of the left and right kidney of Sham and $2 \mathrm{~K} 1 \mathrm{C}$ sedentary (Sed) rats, and rats subjected to exercise training (Ex) without (Ex $0 \%$ ) or with a load corresponding to $3 \%$ of the animal's body weight (Ex $3 \%$ ). No inflammatory process was observed in Sham animals for right and left kidneys (A, B, E, F, I, and J). Also no inflammatory process can be observed in right kidney of 2K1C Ex $0 \%(\mathrm{H})$ and both kidneys of $2 \mathrm{~K} 1 \mathrm{C}$ Ex $3 \%(\mathrm{~K}$ and $\mathrm{L})$. Observe the increase of inflammatory cells in the left and right kidneys of $2 \mathrm{~K} 1 \mathrm{C}$ Sed ( $C$ and $D$, arrows) and in the left kidney of $2 \mathrm{~K} 1 \mathrm{C}$ Ex $0 \%$ rats ( $G$, arrow). All tissues were stained with hematoxylin/eosin. All photomicrographs are enlarged 440 times $($ bar $=25 \mu \mathrm{m}$ ). 


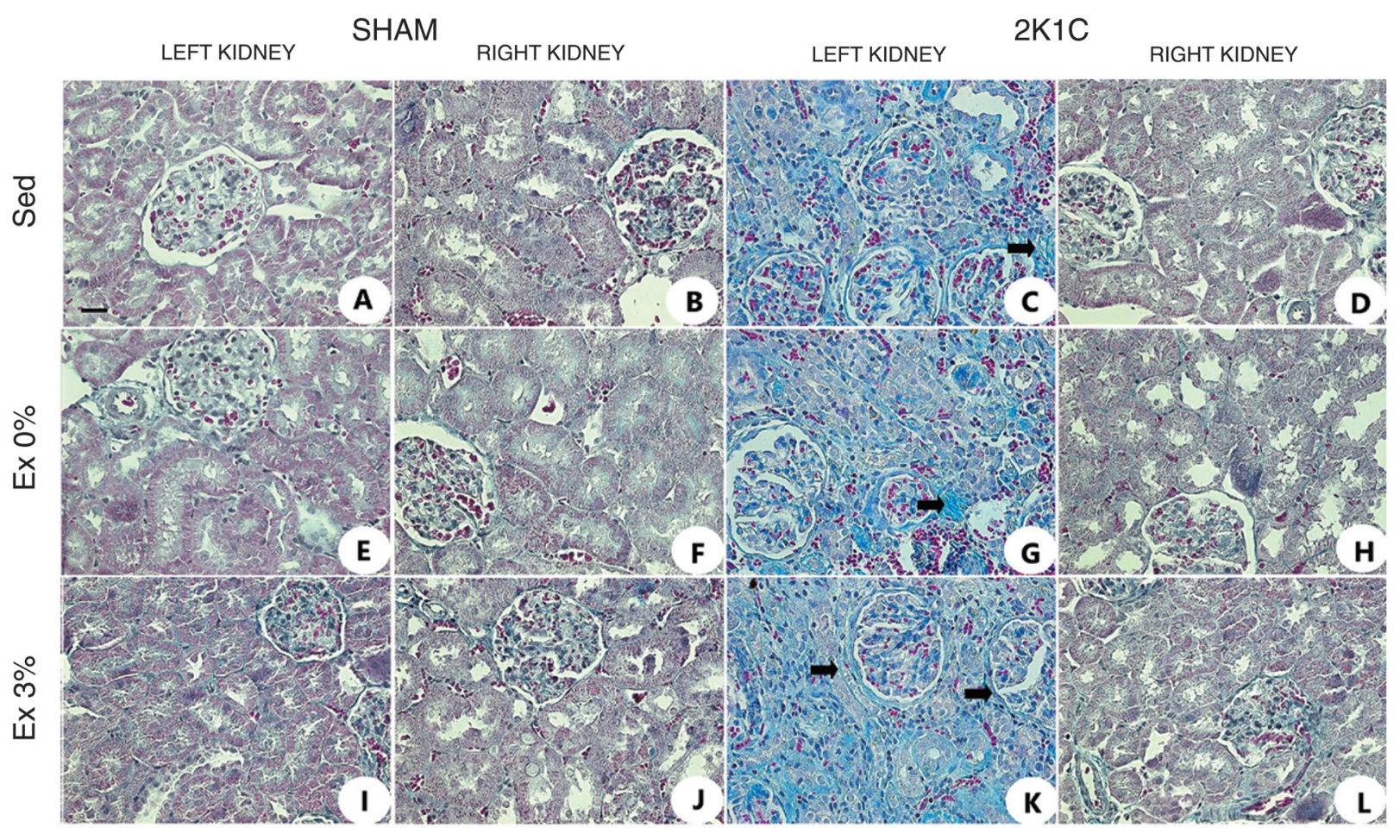

Figure 5. Photomicrographs of left and right kidneys of Sham and $2 \mathrm{~K} 1 \mathrm{C}$ sedentary (Sed) rats, and rats subjected to exercise training (Ex) without (Ex $0 \%$ ) or with a load corresponding to $3 \%$ of the animal's body weight (Ex $3 \%)$. No pathological collagen tissue deposition was observed in Sham animals for right and left kidneys (A, B, E, F, I, and J). Also no collagen tissue deposition can be observed in right kidney of all $2 \mathrm{~K} 1 \mathrm{C}$ animals $(\mathrm{D}, \mathrm{H}, \mathrm{L})$. Observe the greater collagen deposition in the left kidney of $2 \mathrm{~K} 1 \mathrm{C}$ rats $(\mathrm{C}, \mathrm{G}$, and $\mathrm{K}$, arrows). All tissues were stained with Masson's trichrome. All photomicrographs are enlarged 440 times (bar = $25 \mu \mathrm{m})$.

Figure 5). The tissue collagen deposition was greater in the left kidney of $2 \mathrm{~K} 1 \mathrm{C}$ Ex $3 \%$ rats than in the left kidney of $2 \mathrm{~K} 1 \mathrm{C}$ Sed rats (Table 2 and Figure 5). In contrast, Ex 3\% reduced the inflammatory process in clipped and non-clipped kidneys of $2 \mathrm{~K} 1 \mathrm{C}$ rats. The predominant cell type found was mononuclear, similar to that found in the myocardium. However, in 2K1C Ex $0 \%$ rats, the inflammatory process was reduced only in nonclipped kidneys (Table 2 and Figure 4). No differences in tissue collagen deposition in the left or right kidney were observed among Sham animals (Table 2 and Figure 5).

\section{Measurement of lactate}

Lactate production. Figure 6 shows the effect of 5 weeks of swimming on blood lactate concentration in Sham and 2K1C (Sed and Ex) rats. The blood lactate concentration after 30 min of swimming with a load corresponding to $3 \%$ of body weight was higher in $2 \mathrm{~K} 1 \mathrm{C}$ Sed rats $(12.7 \pm 0.5$ $\mathrm{mM}, \mathrm{N}=4)$ compared to Sham Sed rats $(9.3 \pm 0.8 \mathrm{mM}, \mathrm{N}$ $=4)$. However, the blood lactate concentrations of $2 \mathrm{~K} 1 \mathrm{C}$ Ex $0 \%(8.9 \pm 1.2 \mathrm{mM}, \mathrm{N}=4)$ and $2 \mathrm{~K} 1 \mathrm{C}$ Ex $3 \%(7.9 \pm 1.3$ $\mathrm{mM}$ blood lactate, $\mathrm{N}=4$ ) were lower than in $2 \mathrm{~K} 1 \mathrm{C}$ Sed, and were similar to those of Sham Sed rats. No differences in lactate concentrations were observed after $30 \mathrm{~min}$ of swimming with a load corresponding to $3 \%$ of body weight in Sham rats $(10.7 \pm 1 \mathrm{mM}$ in Ex $0 \%$ group, $8.6 \pm 0.5 \mathrm{mM}$

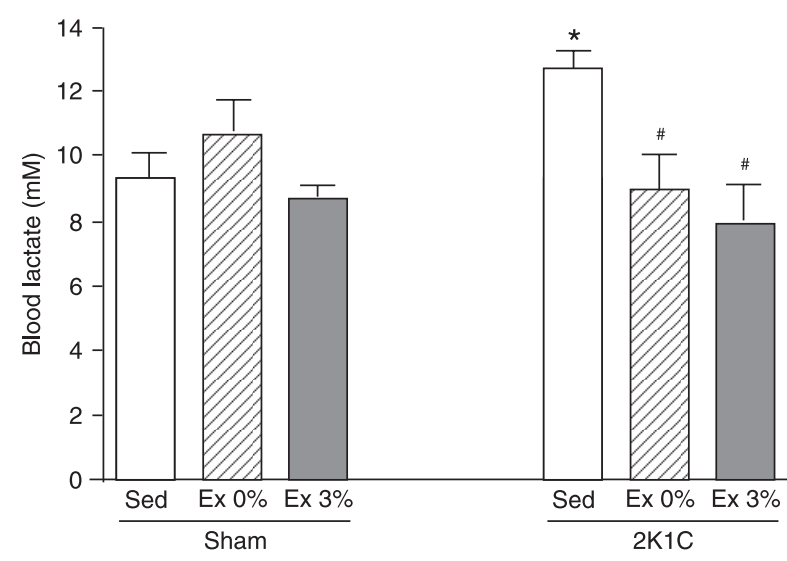

Figure 6. Effect of workload on $2 \mathrm{~K} 1 \mathrm{C}$ rat lactate. Blood lactate $(\mathrm{mM})$ was measured after 30 min of swimming with a workload corresponding to $3 \%$ of body weight in Sham $(\mathrm{N}=4)$ and $2 \mathrm{~K} 1 \mathrm{C}$ $(\mathrm{N}=4)$ sedentary (Sed) rats, and rats subjected to exercise training (Ex) without (Ex 0\%) or with a workload corresponding to $3 \%$ of the animal's body weight (Ex $3 \%$ ). ${ }^{*} P<0.05$ compared to Sham Sed, and ${ }^{\# P}<0.05$ compared to $2 \mathrm{~K} 1 \mathrm{C}$ Sed (ANOVA followed by the Newman-Keuls test).

in Ex $3 \%$ group, and $9.3 \pm 0.8 \mathrm{mM}$ in Sed group; $\mathrm{N}=4$ ) (Figure 6). 


\section{Discussion}

In the present study, we showed that Ex $0 \%$ or Ex $3 \%$ induced similar attenuation in the level of BP and HR of $2 \mathrm{~K} 1 \mathrm{C}$ hypertensive rats. However, only Ex $0 \%$, and not $3 \%$, restored the baroreflex bradycardia in $2 \mathrm{~K} 1 \mathrm{C}$ rats. In addition, Ex $0 \%$ also prevented pathological cardiac hypertrophy and increased the diameter of cardiomyocytes in $2 \mathrm{~K} 1 \mathrm{C}$ rats, whereas Ex $3 \%$ reduced concentric cardiac hypertrophy and increased the inflammatory process and collagen deposition in the myocardium of $2 \mathrm{~K} 1 \mathrm{C}$ rats. Moreover, Ex $3 \%$ prevented an increase in the weight of the non-clipped kidney in $2 \mathrm{~K} 1 \mathrm{C}$ rats and induced increases in the left renal vasculature wall thickness and tissue collagen deposition.

Moderately intense exercise training has been used to induce beneficial effects on the cardiovascular system of animals and humans with hypertension; however, the effects of different intensities of exercise are not entirely understood. The use of different workload intensities is common in swimming protocols for rats. Most studies have used loads between 5 and $8 \%(15,25,26)$. However, Gobatto et al. (15) suggested that the use of loads higher than $6 \%$ of body weight could lead to undesirable effects related to the intensity of exercise training, such as muscle lesions and incomplete restoration of substrate levels between exercise sessions.

Prada et al. (27) showed that rats subjected to swimming training for 4 weeks with a load calculated as $4.95 \%$ of body weight had an exercise intensity equivalent to the anaerobic threshold. Although we were unable to evaluate the exercise intensity in the present study, we believe that Ex 3\% training corresponded to an intensity lower than the anaerobic threshold, i.e., it was of low to moderate intensity at least for Sham animals. In previous experiments, $2 \mathrm{~K} 1 \mathrm{C}$ rats $(\mathrm{N}$ $=16$ ) were subjected to swimming training using a load of $5 \%$ of their body weight. However, $50 \%$ of these animals did not tolerate this load, and died between the second and third week of training (data not shown), suggesting that this exercise intensity was above the anaerobic threshold, in agreement with studies by Prada et al. (27).

Under normal conditions, during exercise in an $\mathrm{VO}_{2}-$ steady state (aerobic), most of the lactate produced is removed from the blood $(28,29)$. However, there are no reports in the literature about the kinetics of blood lactate in rats with hypertension. Although the present study did not evaluate the anaerobic threshold of the animals (2K1C or Sham), training improved the lactate kinetics in $2 \mathrm{~K} 1 \mathrm{C}$ hypertensive rats, since blood lactate concentrations in Ex $0 \%$ and $\mathrm{Ex} 3 \% 2 \mathrm{~K} 1 \mathrm{C}$ rats, measured after swimming with a load of $3 \%$ of body weight, were lower than those found in $2 \mathrm{~K} 1 \mathrm{C}$ Sed rats and similar to those of Sham Sed rats. Furthermore, our data demonstrated that $2 \mathrm{~K} 1 \mathrm{C}$ Sed rats showed a rise in blood lactate levels compared to the other groups, suggesting that in hypertension there is impairment in the relationship between the production and removal of lactate during exercise.

Despite these concerns, in the present study Ex 0\% and Ex $3 \%$ had similar effects in lowering BP and HR in $2 \mathrm{~K} 1 \mathrm{C}$ hypertensive rats. However, this different workload (Ex $0 \%$ or Ex $3 \%$ ) of exercise training had different effects on the baroreflex bradycardia, on left ventricle remodeling induced by hypertension, and on morphometric changes in the clipped kidney of $2 \mathrm{~K} 1 \mathrm{C}$ rats.

The data showed that Ex $0 \%$ was effective in reducing high $\mathrm{BP}$ and $\mathrm{HR}$, and restored the baroreflex bradycardia in $2 \mathrm{~K} 1 \mathrm{C}$ rats, confirming our previous study using the same model of hypertensive $2 \mathrm{~K} 1 \mathrm{C}$ rats (10), as well as other studies that showed that low-intensity exercise training can induce important changes in the cardiovascular system in animals and humans with hypertension $(6,7,14,30)$; however, the mechanisms underlying this effect are not well understood. Some studies have suggested that the increase in baroreflex sensitivity is induced by the improvement of the vagal component $(7,31,32)$, and others suggest that the sympathetic component of the baroreflex function is attenuated $(32,33)$. However, in the present study, in contrast to Ex $0 \%$, which induced an improvement of baroreflex sensitivity, Ex $3 \%$ did not change the relatively lower sensitivity of the reflex bradycardia of $2 \mathrm{~K} 1 \mathrm{C}$ rats. Studies in humans and animals have found increases $(5,30)$, decreases $(34)$, or no changes (35) in baroreflex sensitivity after various exercise training protocols. There is no definitive explanation for the different effects of Ex $0 \%$ and Ex $3 \%$ on the baroreflex of $2 \mathrm{~K} 1 \mathrm{C}$ rats observed in the present study. It is possible that Ex $3 \%$ increased the sympathetic drive in some specific territories so intensively that it overcame the benefits of exercise training (Ex $3 \%$ ), at least in $2 \mathrm{~K} 1 \mathrm{C}$. Data from the present study that reinforce this notion are the lack of an increase in weight of the non-clipped kidney, the increase in the left (clipped) renal vasculature wall thickness, and the greater increase in tissue collagen deposition in the clipped kidney of $2 \mathrm{~K} 1 \mathrm{C}$ Ex $3 \%$ rats compared to the $2 \mathrm{~K} 1 \mathrm{C}$ Sed rats. Overall, this result suggests that renal sympathetic activity might be greater in $2 \mathrm{~K} 1 \mathrm{C}$ Ex $3 \%$ rats than in $2 \mathrm{~K} 1 \mathrm{C}$ Ex $0 \%$ rats. In agreement with this suggestion, studies $(6,36,37)$ have shown that high-intensity exercise training appears to be less effective in inducing cardiovascular benefits in SHR, because there is such a high sympathetic drive during high-intensity exercise that they never recover completely after each exercise session. Considering the data as a whole, these morphometric changes and the lack of improvement in the sensitivity of the reflex bradycardia in $2 \mathrm{~K} 1 \mathrm{C}$ Ex $3 \%$ rats may be triggered by the imbalance between the $2 \mathrm{~K} 1 \mathrm{C}$ Ex $3 \%$ training and complete recovery after each exercise session, which could lead to activation of the sympathetic system. Moreover, the evaluation of the correlation between reflex bradycardic and morphometric changes of the kidney (left renal vasculature wall thickness by lumen ratio and collagen deposition in the left kidney) showed a negative correlation $(r=-0.8808$ and $r=-0.8255$, 
respectively). The present correlations are consistent with published data $(8,38)$ showing the important role of afferent signaling driven by baroreceptors to improve the beneficial effects of exercise training in reducing bradycardia and BP and normalizing the increased wall/lumen ratio of skeletal muscles and kidney arterioles in SHR.

Cardiac hypertrophy occurs in response to various stimuli, such as pressure and volume overload. Exercise training is mainly related to a volume overload induced by cardiac eccentric hypertrophy, with predominant longitudinal myocyte growth (3). Although myocyte length was not determined in the present study, we were able to show changes in myocyte width. This is consistent with the eccentric hypertrophy induced by exercise training, which can lead to proportional growth of myocyte width and length (39). A variety of hemodynamic mechanisms that may account for hypertensive vascular disease include coronary arteriolar compression by the hypertrophied and stiffer left ventricle, increased arteriolar wall thickness/lumen ratio, and increased left ventricle chamber diameters, reflecting not only myocyte hypertrophy but also collagen deposition (40). The present data showed that Ex $0 \%$ prevented cardiac concentric hypertrophy, increased cardiomyocyte diameter, and decreased the cardiac vasculature wall thickness/lumen ratio in $2 \mathrm{~K} 1 \mathrm{C}$ rats. Together, all of these morphometric changes likely increase the efficiency of cardiac function, which could contribute to lowering the BP and $\mathrm{HR}$ of $2 \mathrm{~K} 1 \mathrm{C}$ Ex $0 \%$ animals. On the other hand, $2 \mathrm{~K} 1 \mathrm{C}$ Ex $3 \%$ rats showed a reduction of concentric remodeling, prevention of the increase in the cardiac vasculature wall thickness, decreased cardiomyocyte diameter, and also an increased number of myocardial cells and increased collagen deposition. Despite this increased collagen deposition, Ex $3 \%$ induced attenuation of baseline MAP and HR in $2 \mathrm{~K} 1 \mathrm{C}$ rats. In this respect, we believe that this increased collagen deposition observed in $2 \mathrm{~K} 1 \mathrm{C}$ rats subjected to exercise

\section{References}

1. Yamazaki T, Komuro I, Yazaki Y. Role of the renin-angiotensin system in cardiac hypertrophy. Am J Cardiol 1999; 83: $53 \mathrm{H}-57 \mathrm{H}$.

2. Colan SD. Mechanics of left ventricular systolic and diastolic function in physiologic hypertrophy of the athlete's heart. Cardiol Clin 1997; 15: 355-372.

3. Lorell BH, Carabello BA. Left ventricular hypertrophy: pathogenesis, detection, and prognosis. Circulation 2000; 102: 470-479.

4. Medeiros A, Oliveira EM, Gianolla R, Casarini DE, Negrao $\mathrm{CE}$, Brum PC. Swimming training increases cardiac vagal activity and induces cardiac hypertrophy in rats. Braz J Med Biol Res 2004; 37: 1909-1917.

5. Liu JL, Irvine S, Reid IA, Patel KP, Zucker IH. Chronic exercise reduces sympathetic nerve activity in rabbits with pacing-induced heart failure: A role for angiotensin II. CircuIation 2000; 102: 1854-1862. training with a load of $3 \%$ was not long enough to totally compromise cardiac function. Perhaps, with a longer Ex $3 \%$ training time (more than 5 weeks), the level of collagen deposition could increase and compromise cardiac function. Another consideration about the present study is related to the quantitative morphometric analysis performed. Future qualitative analyses involving types of collagen, inflammatory cell screening and others are necessary to elucidate the extent of tissue damage and the repercussions of such damage on cardiac and renal function.

The sedentary hypertensive $2 \mathrm{~K} 1 \mathrm{C}$ rats showed no alteration in the number of myocardial cells or in tissue collagen deposition, as also observed in $2 \mathrm{~K} 1 \mathrm{C}$ Ex $3 \%$ rats. Our explanation is based on the short period of renovascular hypertension ( 5 weeks after clipping of the renal artery). Moreover, during recovery, an additive effect between sympathetic activity and RAS hyperactivity in the $2 \mathrm{~K} 1 \mathrm{C}$ Ex $3 \%$ rats may have contributed to the changes observed in renal and cardiac remodeling in the animals subjected to this exercise workload.

Overall, the present study showed that Ex $0 \%$ or Ex $3 \%$ had beneficial effects on high BP and HR, as well as on cardiac dysfunction in $2 \mathrm{~K} 1 \mathrm{C}$ rats. Nevertheless, the data suggest that Ex $0 \%$ is better for improving the cardiac alterations observed in renovascular hypertensive rats, since Ex 3\% did not change the relatively lower sensitivity of the reflex bradycardia or prevent the cardiac lesions induced by hypertension.

\section{Acknowledgments}

Research supported by FAPEMIG-RedeToxifar, CNPq, INCT-FAPEMIG-CNPq, Pronex Project Grant (FAPEMIG/ CNPq), and CAPES. E.R. Soares was the recipient of a FAPEMIG fellowship (Master's Degree, Programa de PósGraduação em Ciências Biológicas), NUPEB, UFOP.
6. Veras-Silva AS, Mattos KC, Gava NS, Brum PC, Negrao CE, Krieger EM. Low-intensity exercise training decreases cardiac output and hypertension in spontaneously hypertensive rats. Am J Physiol 1997; 273: $\mathrm{H} 2627-\mathrm{H} 2631$.

7. Brum PC, Da Silva GJ, Moreira ED, Ida F, Negrao CE, Krieger EM. Exercise training increases baroreceptor gain sensitivity in normal and hypertensive rats. Hypertension 2000; 36: 1018-1022.

8. Ceroni A, Chaar LJ, Bombein RL, Michelini LC. Chronic absence of baroreceptor inputs prevents training-induced cardiovascular adjustments in normotensive and spontaneously hypertensive rats. Exp Physiol 2009; 94: 630-640.

9. Boissiere J, Lemaire MC, Antier D, Courteix D, Bonnet P. Exercise and vasorelaxing effects of CO-releasing molecules in hypertensive rats. Med Sci Sports Exerc 2006; 38: 652659.

10. Rodrigues MC, Campagnole-Santos MJ, Machado RP, Silva 
ME, Rocha JL, Ferreira PM, et al. Evidence for a role of AT(2) receptors at the CVLM in the cardiovascular changes induced by low-intensity physical activity in renovascular hypertensive rats. Peptides 2007; 28: 1375-1382.

11. Evangelista FS, Brum PC, Krieger JE. Duration-controlled swimming exercise training induces cardiac hypertrophy in mice. Braz J Med Biol Res 2003; 36: 1751-1759.

12. Wisloff U, Stoylen A, Loennechen JP, Bruvold M, Rognmo O, Haram PM, et al. Superior cardiovascular effect of aerobic interval training versus moderate continuous training in heart failure patients: a randomized study. Circulation 2007; 115: 3086-3094.

13. Tipton $\mathrm{CM}$, Matthes RD, Marcus KD, Rowlett KA, Leininger JR. Influences of exercise intensity, age, and medication on resting systolic blood pressure of SHR populations. J Appl Physiol 1983; 55: 1305-1310.

14. Fagard RH, Thijs LB, Amery AK. The effect of gender on aerobic power and exercise hemodynamics in hypertensive adults. Med Sci Sports Exerc 1995; 27: 29-34.

15. Gobatto CA, de Mello MA, Sibuya CY, de Azevedo JR, dos Santos LA, Kokubun E. Maximal lactate steady state in rats submitted to swimming exercise. Comp Biochem Physiol A Mol Integr Physiol 2001; 130: 21-27.

16. Kagiyama S, Varela A, Phillips MI, Galli SM. Antisense inhibition of brain renin-angiotensin system decreased blood pressure in chronic 2-kidney, 1 clip hypertensive rats. Hypertension 2001; 37: 371-375

17. Lazartigues E, Lawrence AJ, Lamb FS, Davisson RL. Renovascular hypertension in mice with brain-selective overexpression of AT1a receptors is buffered by increased nitric oxide production in the periphery. Circ Res 2004; 95: 523-531.

18. Becker LK, Santos RA, Campagnole-Santos MJ. Cardiovascular effects of angiotensin II and angiotensin-(1-7) at the RVLM of trained normotensive rats. Brain Res 2005; 1040 : 121-128.

19. Galdino da Silva R, Mello MAR. Efeitos da ingestão de dieta hipoprotéica e de exercício físico moderado sobre a evolução da gestação e o desenvolvimento fetal em ratas jovens. Rev Paul Educ Fís 2000; 14: 118-127.

20. Alzamora AC, Santos RA, Campagnole-Santos MJ. Baroreflex modulation by angiotensins at the rat rostral and caudal ventrolateral medulla. Am J Physiol Regul Integr Comp Physiol 2006; 290: R1027-R1034.

21. Loud AV, Anversa P, Giacomelli F, Wiener J. Absolute morphometric study of myocardial hypertrophy in experimental hypertension. I. Determination of myocyte size. Lab Invest 1978; 38: 586-596.

22. Melo RM, Martinho E Jr, Michelini LC. Training-induced, pressure-lowering effect in SHR: wide effects on circulatory profile of exercised and nonexercised muscles. Hypertension 2003; 42: 851-857.

23. Caliari MV, do Pilar Machado R, de Lana M, Caja RA, Carneiro CM, Bahia MT, et al. Quantitative analysis of cardiac lesions in chronic canine chagasic cardiomyopathy. Rev Inst Med Trop Sao Paulo 2002; 44: 273-278.

24. de Paula Costa G, Silva RR, Pedrosa MC, Pinho V, de Lima WG, Teixeira MM, et al. Enalapril prevents cardiac immune- mediated damage and exerts anti-Trypanosoma cruzi activity during acute phase of experimental Chagas disease. Parasite Immunol 2010; 32: 202-208.

25. Pereira B, Costa Rosa LF, Safi DA, Medeiros MH, Curi R, Bechara EJ. Superoxide dismutase, catalase, and glutathione peroxidase activities in muscle and lymphoid organs of sedentary and exercise-trained rats. Physiol Behav 1994; 56: 1095-1099.

26. Galdino RMS, Almeida CCS, Luciano E, Mello MAR. Protein malnutrition does not impair glucose metabolism adaptations to exercise-training. Nutr Res 2000; 20: 527-535.

27. Prada FJA, Voltarelli FA, Oliveira CAM, Gobatto CA, Macedo DV, Mello MAR. Aerobic condition and oxidative stress in rats swim-trained at the anaerobic threshold intensity. $R$ Bras Ci Mov 2004; 12: 29-34.

28. Beneke R, Hutler M, Leithauser RM. Maximal lactatesteady-state independent of performance. Med Sci Sports Exerc 2000; 32: 1135-1139.

29. Billat VL, Sirvent P, Py G, Koralsztein JP, Mercier J. The concept of maximal lactate steady state: a bridge between biochemistry, physiology and sport science. Sports Med 2003; 33: 407-426.

30. Somers VK, Conway J, Johnston J, Sleight P. Effects of endurance training on baroreflex sensitivity and blood pressure in borderline hypertension. Lancet 1991; 337: 1363-1368.

31. Liu JL, Kulakofsky J, Zucker IH. Exercise training enhances baroreflex control of heart rate by a vagal mechanism in rabbits with heart failure. J Appl Physiol 2002; 92: 2403-2408.

32. Minami N, Yoshikawa T, Kataoka H, Mori N, Nagasaka M, Kurosawa $\mathrm{H}$, et al. Effects of exercise and beta-blocker on blood pressure and baroreflexes in spontaneously hypertensive rats. Am J Hypertens 2003; 16: 966-972.

33. Kramer JM, Beatty JA, Plowey ED, Waldrop TG. Exercise and hypertension: a model for central neural plasticity. Clin Exp Pharmacol Physiol 2002; 29: 122-126.

34. Mack GW, Thompson CA, Doerr DF, Nadel ER, Convertino VA. Diminished baroreflex control of forearm vascular resistance following training. Med Sci Sports Exerc 1991; 23: 1367-1374.

35. Sheldahl LM, Ebert TJ, Cox B, Tristani FE. Effect of aerobic training on baroreflex regulation of cardiac and sympathetic function. J Appl Physiol 1994; 76: 158-165.

36. Budgett R. Overtraining syndrome. Br J Sports Med 1990; 24: 231-236.

37. Kentta G, Hassmen P. Overtraining and recovery. A conceptual model. Sports Med 1998; 26: 1-16.

38. Moraes-Silva IC, De La Fuente RN, Mostarda C, Rosa K, Flues K, Damaceno-Rodrigues NR, et al. Baroreflex deficit blunts exercise training-induced cardiovascular and autonomic adaptations in hypertensive rats. Clin Exp Pharmacol Physiol 2010; 37: e114-e120.

39. Claessens P, Claessens C, Claessens M, Bloemen H, Verbanck M, Fagard R. Ventricular premature beats in triathletes: still a physiological phenomenon? Cardiology 1999; 92: 28-38.

40. Frohlich ED. Ischemia and fibrosis: the risk mechanisms of hypertensive heart disease. Braz J Med Biol Res 2000; 33: 693-700. 